\title{
Activated ovarian endothelial cells promote early follicular development and survival
}

\author{
Alon Kedem ${ }^{1,2^{*}}{ }$, Anate Aelion-Brauer ${ }^{1 *}{ }^{*}$, Peipei Guo ${ }^{2}$, Duancheng Wen², Bi-Sen Ding ${ }^{2}$, Raphael Lis ${ }^{2}$, Du Cheng ${ }^{2}$, \\ Vladislav M. Sandler ${ }^{2}$, Shahin Rafii ${ }^{2}$ and Zev Rosenwaks ${ }^{1,2}$
}

\begin{abstract}
Background: New data suggests that endothelial cells (ECs) elaborate essential "angiocrine factors". The aim of this study is to investigate the role of activated ovarian endothelial cells in early in-vitro follicular development.

Methods: Mouse ovarian ECs were isolated using magnetic cell sorting or by FACS and cultured in serum free media. After a constitutive activation of the Akt pathway was initiated, early follicles (50-150 um) were mechanically isolated from 8-day-old mice and co-cultured with these activated ovarian endothelial cells (AOEC) $(n=32)$, gel $(n=24)$ or within matrigel $(n=27)$ in serum free media for 14 days. Follicular growth, survival and function were assessed.

Results: After 6 passages, flow cytometry showed 93\% of cells grown in serum-free culture were VE-cadherin positive, CD-31 positive and CD 45 negative, matching the known EC profile. Beginning on day 4 of culture, we observed significantly higher follicular and oocyte growth rates in follicles co-cultured with AOECs compared with follicles on gel or matrigel. After 14 days of culture, $73 \%$ of primary follicles and $83 \%$ of secondary follicles co-cultured with AOEC survived, whereas the majority of follicles cultured on gel or matrigel underwent atresia.

Conclusions: This is the first report of successful isolation and culture of ovarian ECs. We suggest that co-culture with activated ovarian ECs promotes early follicular development and survival. This model is a novel platform for the in vitro maturation of early follicles and for the future exploration of endothelial-follicular communication.
\end{abstract}

Capsule: In vitro development of early follicles necessitates a complex interplay of growth factors and signals required for development. Endothelial cells (ECs) may elaborate essential "angiocrine factors" involved in organ regeneration. We demonstrate that co-culture with ovarian ECs enables culture of primary and early secondary mouse ovarian follicles.

Keywords: Endothelial cells, in-vitro maturation, Follicle culture, Follicular activation

\section{Background}

Advancements in cancer treatment continue to improve survival and cure rates in women of reproductive age. Many, however, will struggle with ovarian failure and premature menopause as a consequence of potentially gonadotoxic chemotherapy and radiation [1]. Among the options currently available for fertility preservation in these patients is cryopreservation and future auto-transplantation of ovarian cortical tissue containing immature follicles [2,3]. While excellent progress has been made in this clinical arena, efficiency of such a technique remains compromised secondary

\footnotetext{
*Correspondence: kedem2001@gmail.com; aaelion@gmail.com

${ }^{\dagger}$ Equal contributors

${ }^{1}$ The Center for Reproductive Medicine and Infertility, Weill Cornell Medical College, New York, NY 10021, USA

Full list of author information is available at the end of the article
}

to a period of hypoxia following grafting [4-6]. Additionally, this technique carries the risk of potentially reintroducing malignancies [7]. These drawbacks could be overcome by the ability to mature early follicles in vitro. The development of this approach is currently hampered by the lack of knowledge regarding signals responsible for early follicle activation. Duplicating the complex interaction of growth factors, cellular and hormonal signals required for follicular development and oocyte maturation in vitro is challenging.

During embryogenesis, endothelial cells (ECs) induce organogenesis before the development of circulation [8-11]. These findings suggest that ECs not only serve as conduits to deliver nutrients and oxygen, but may also be instrumental in establishing an instructive, organ-specific roadmap through which elaboration of paracrine trophogens stimulate regeneration. These elaborate signals promoted by ECs 
have been termed "angiocrine factors" and have been shown to be crucial for the maintenance of organ-specific tissues and tumor cells [12]. ECs contribute to self-renewal of hematopoietic stem cells [13-15] and neuronal stem cells [16]. They promote the growth of leukemic cells [17], gliomas [18] and more recently, liver and lung regeneration have been found to be dependent on specific angiocrines [19]. Angiogenesis has also been shown as critical in the process of early follicular development. Angiogenesis begins within the stroma during early follicular development [20]. Primordial and primary follicles receive their nutrition and oxygen supply via passive diffusion from stromal blood vessels. Stromal cells that surround follicles in the secondary stage or later become organized into thecal layers, in which the innermost part contains blood vessels. This vascular system is thought to provide various paracrine factors necessary for folliculogenesis, most notably VEGF [21]. However, hurdles associated with cultivating functional primary endothelial cells in long term in vitro culture systems have hindered their use. To bypass this problem, Seandel and Rafii et al. demonstrated that primary endothelial cells can be transduced with an adenovirus gene, early region 4 encoded open reading frame-1 (E4ORF1), which leads to chronic activation of Akt, thereby blocking apoptosis and enabling culture of primary endothelial cells for weeks, while maintaining their angiogenic profiles [22]. Incorporating primary mouse ovarian Akt-activated ECs, we propose a novel, serum free, in vitro follicle growth system that promotes activation and development of early follicles by providing follicles with appropriate angiocrines, at the appropriate time, and maintains the essential communication between ECs and follicles.

This study aims to analyze the distinct characteristics of ovarian endothelial cells and to apply this novel platform as an in-vitro system to induce follicular maturation for fertility preservation.

\section{Methods}

\section{Animals}

All animal procedures performed in the study were reviewed and approved by the Institutional Animal Care and Use Committee. C57BL/6 (B6) mice were used in this study.

\section{Isolation and culture of ECs from murine ovaries}

Six-week-old B6 female mice were euthanized, and their ovaries surgically removed with sterile technique. Ovaries were placed in HBSS supplemented with 1\% Penicillin/ Streptomycin/Amphotericin B solution (Life Technologies, Norwalk, CT) and minced with surgical scissors. Minced ovarian tissue was re-suspended in HBSS solution, spun down and supernatant discarded. Tissue was digested with Collagenase A (Roche, Nutley, NJ) at a concentration of $2.5 \mathrm{mg} / \mathrm{ml}$ for $45 \mathrm{~min}$ at $37^{\circ} \mathrm{C}$ with constant, gentle tilting.
Once fully digested, ovarian tissue was filtered through a sterile 40um cell strainer. The flow-through was centrifuged at 1200 RMP for 5 min and supernatant carefully aspirated. Room temperature dilute lysis buffer (BD Pharmingen Franklin Lakes, NJ) was used for red blood cell lysis. Cells were then counted using a grid.

Isolation of murine ovarian ECs with magnetic bead sorting Sheep anti-rat Dyna beads (Invitrogen Carlsbad, CA) were coated with rat anti-mouse CD31 antibody, a known endothelial cell marker (Ten $\mu \mathrm{l}$ of rat anti-mouse CD-31 antibody per $10 \mu \mathrm{l}$ beads) (Clone 13.3, BD Pharmingen) as per manufacturer protocol. Ten microliters of beads were used per 10 ovaries. Beads were incubated overnight at $4{ }^{\circ} \mathrm{C}$. When ready for use, beads were washed three times with PBS, 0.1\% BSA, 2 mM EDTA and 1\% Penicillin/Streptomycin/Amphotericin B solution (Life Technologies) to remove excess antibody. Beads were re-suspended in $50 \mu \mathrm{l}$ of the above washing solution until they were ready for use.

Ten microliters of CD-31 coated beads were added per $1 \times 10^{6}$ cells counted. The cells were incubated for 45 min at $4{ }^{\circ} \mathrm{C}$ with constant, gentle tilting. After incubation, bead bound cells were collected with a magnetic particle concentrator (Invitrogen Norwalk, CT) and washed five times with $\mathrm{PBS}+0.1 \% \mathrm{BSA}+2 \mathrm{mM}$ EDTA $+1 \%$ Penicillin/Streptomycin/Amphotericin B (Life Technologies).

\section{Isolation of murine ovarian ECs using fluorescence activated cell sorting}

Twenty-five micrograms of VE-Cadherin (BV13, Biolegend San Diego, CA)-Alexa Fluor 647 was injected retroorbitally under anesthesia $8 \mathrm{~min}$ prior to sacrifice and organ harvest. For flow sorting, ovaries were minced and incubated with Collagenase A ( $25 \mathrm{mg} / \mathrm{ml})$, Dispase II $(25 \mathrm{mg} /$ $\mathrm{ml}$ ), and DNase $(250 \mu \mathrm{g} / \mathrm{ml})$ (Roche) at $37{ }^{\circ} \mathrm{C}$ for 20 30 min to create a single cell suspension. Cells were filtered through a $40 \mu \mathrm{m}$ filter immediately prior to analysis. Post digestion staining was performed with CD31 and nonendothelial antibodies CD45 (30-F11, BD Pharmingen), rat and mouse IgG (Jackson Laboratories, Farmington, CT). All flow cytometry was performed on a LSRII SORP. All flow sorting was performed on an AriaII SORP. Data analysis was done with BD FACS Diva software (Becton Dickenson). Antibody captured beads were used to calculate compensation (BD Pharmingen). FSC-H vs. FSC-W and SSC-H vs. SSC-W were analyzed to exclude cell doublets. All manufacturers recommended quality control tests were performed immediately prior to sorting.

\section{Ovarian EC culturing}

Primary ovarian ECs (POECs) were re-suspended in 500ul of EC growth media containing Nutrient Mixture F12 Ham (Sigma-Aldrich St Louis, MO), Low glucose DMEM 
(Sigma-Aldrich), Penicillin/Streptomycin/Amphotericin B solution (Life Technologies), MEM Non-Essential Amino Acids (Life Technologies), 1 M HEPES (Life Technologies), KnockOut ${ }^{\mathrm{Tm}}$ Serum Replacement(Life Technologies), $10 \mathrm{mg} / \mathrm{ml}$ heparin stock (Sigma-Aldrich), $7.5 \mathrm{mg} / \mathrm{ml}$ endothelial cell mitogen (Biomedical Technologies Stoughton, MA) and transferred to fibronectin (Sigma-Aldrich) coated plates.

On day 7 of culture, POECs were transduced with myristoylated-AKT1 (myr-AKT) lentiviruses as previously described [15].

Flow cytometry purity confirmation was done after 6 passages. Cells were stained with VE-Cadherin, CD31, CD45 and Dapi (Sigma-Aldrich). All cells were blocked prior to staining and analyzed using a LSRII SORP (BD Biosciences).

\section{Angiocrine profiling of ovarian endothelial cells}

Total RNA was extracted from POEC (isolated by FACS) by the Mini RNA Isolation I Kit (Zymo Research Corp., Irvine, CA), according to manufacturers' protocol. Total RNA (100 ng) from each sample was used for cDNA synthesis using high capacity real-time (RT)-PCR Kit (Applied Biosystems, Carlsbad, CA) according to manufacturer's protocol: $37{ }^{\circ} \mathrm{C}$ for $120 \mathrm{~min}$ followed by $85{ }^{\circ} \mathrm{C}$ for $5 \mathrm{~min}$ with random hexamer primers $(25 \mathrm{ng} / \mu \mathrm{l}$ final concentration) in a $10 \mu \mathrm{l}$ total volume reaction.

RT-PCR reaction mix contained cDNA, Fast SYBR Green Master Mix (Applied Biosystems) and specific primers for VE-cadherin, FLK1, VEGF-A, PDGF, FGF1, VWF, Notch1, Notch2, Notch3, Notch4, Dll1, Dll4, Jagged1, Jagged2, and $\beta$-actin (endogenous control) in a total volume of $10 \mu \mathrm{l}$ Reaction was performed in a StepOne plus RT-PCR apparatus (Applied Biosystems). Cycling parameters were $20 \mathrm{~s}$ at $95{ }^{\circ} \mathrm{C}, 40$ cycles at $95{ }^{\circ} \mathrm{C}$ for $3 \mathrm{~s}$ and at $60{ }^{\circ} \mathrm{C}$ for $30 \mathrm{~s}$. A melting curve analysis was performed at the end of each run to ensure a single amplicon. Analysis of qRT-PCR results was carried out using StepOne software (Applied Biosystems). Relative gene expression was calculated using the delta-delta Ct method.

\section{Murine ovarian follicle isolation}

Intact ovaries from euthanized 8-day-old B6 mice were removed under sterile conditions and immediately placed in warmed dissecting media composed of Waymouth MB752 (Sigma-Aldrich) supplemented with Penicillin/ Streptomycin/Amphotericin B solution and 10\% Fetal Bovine Serum (Life Technologies). Oocyte-granulosa complexes were mechanically isolated using insulin gauge syringes under a dissecting microscope. Intact complexes measuring 50-150 $\mu \mathrm{m}$ were washed, isolated and, with drawn glass micropipettes, transferred to wells containing one of three culture platforms.

\section{Follicular culture}

Individual follicles were cultured for 14 days on one of the following platforms: 1) AOEC + follicular culture media $(n=32)$, 2) Matrigel + follicular culture media $(n=27)$, 3) Gelatin + follicular culture media $(n=24)$. Experiments were run in parallel (Fig. 3a).

All experiments were carried out in 48-well plates. AOEC co-culture plates were prepared by first coating plates with fibronectin. Briefly, $0.5 \mathrm{ml}$ of dilute fibronectin (Sigma-Aldrich, diluted 1:1000 in PBS) was added to plates. Plates remained at room temperature for $30 \mathrm{~min}$ after which solution was removed by aspiration. Plates were then seeded with 0.5 million endothelial cells per plate. Matrigel (BD Biosciences) plates were prepared as previously described with slight modification [23]. Briefly, Matrigel was liquefied at $4{ }^{\circ} \mathrm{C}$ and diluted in a 1:1 ratio with follicular culture media. Plates were then maintained at $37{ }^{\circ} \mathrm{C}$ for one hour to allow for polymerization. Gelatin (Sigma-Aldrich) plates were coated as per manufacturer protocol. 200u $\mathrm{ul}$ of follicular culture media was added to all plates.

The individual placing the follicles into the various wells was blinded to platform. Half of the media from each well was exchanged for fresh media every second day. Culture media included: Waymouth MB752 supplemented with $0.23 \mathrm{mM}$ pyruvic acid (Sigma-Aldrich), Penicillin/Streptomycin/Amphotericin B solution (Life Technologies), $10 \mathrm{mIU} / \mathrm{ml}$ recombinant FSH (Merck, Whitehouse Station, $\mathrm{NJ}), 5 \mu \mathrm{g} / \mathrm{ml}$ each of insulin, transferrin and selenium (ITS, Becton Dickinson), $1 \mathrm{mg} / \mathrm{ml}$ fetuin (Sigma-Aldrich) and 10\% KnockOut ${ }^{\mathrm{Tm}}$ Serum Replacement (Life Technologies). Throughout the 14 days of culture, oocyte-cumulus complexes were maintained at $37^{\circ} \mathrm{C}$ in a Forma ${ }^{\text {Tm }}$ Series 3 Water Jacketed $\mathrm{CO} 2$ Incubator with 5\% CO2 and humidified air.

\section{Follicular and oocyte measurements}

Each individual follicle was observed and photographed every second day using a Nikon-2000 U inverted microscope with digital imager. All photographs were imported into ImageJ software (version 1.48, National Institutes of Health) for measurement. Two perpendicular diameters of follicles were measured. The mean of two diameters was calculated and considered as the reference diameter of the follicle. Diameters of oocytes were taken in the same fashion. The first day of culture was considered day 0. Follicular atresia was characterized by absence of growth, a decrease in diameter and extrusion of the oocyte.

\section{Estradiol measurements}

In order to obtain potential hormonal measurements, we cultured 5 secondary follicles $(100-150 \mu \mathrm{m})$ in each well. $1 / 2$ media was collected and replaced every second day. This substituted media was stored individually in eppendorf tubes at $-20{ }^{\circ} \mathrm{C}$. Estradiol measurements were 
analyzed using DPC immulite 2000 immunoassay system (Seimens Healthcare, Tarrytown, NY). Media from wells containing no follicles was used as controls.

\section{Isolation of Mouse Tail Fibroblasts (MTF)}

Tail and ear biopsies were taken from 6-week-old B6 mice under sterile conditions. Tissue was minced and incubated at $37^{\circ}$ for $45 \mathrm{~min}$ in trypsin-EDTA (Life Technologies). The trypsin was deactivated with $20 \%$ fetal bovine serum (FBS) in DMEM (Gibco/Life Technologies) with 1\% Penicillin/ Streptomycin/Amphotericin B solution (Life Technologies). After $48 \mathrm{~h}$ the media was replaced with $10 \%$ FBS in DMEM with 1\% Penicillin/Streptomycin/Amphotericin B solution and the cells were allowed to expand for 10-14 days.

\section{TUNEL and Ki67 staining}

In order to detect apoptosis in oocytes and granulosa cells, follicles co-cultured on AOECs or MTF for 7 days were analyzed for DNA fragmentation with TUNEL reaction. TUNEL reaction was performed according to manufacturer's labeling protocol for adherent cells (Roche).

In order to detect markers of proliferation in granulosa cells on day 7 of co-culture with AOECs or MTF, follicles from each group were stained with Ki67 (stain for proliferating cells) according to manufacturer's protocol (abcam Cambridge, MA).

All cells were photographed on a Zeiss LSM 710 microscope equipped with epifluorescent optics.

\section{Presentation of data and statistical analysis}

Two Groups were created for analysis: follicles $<100 \mu \mathrm{m}$ (Primary follicles) and follicles $>100 \mu \mathrm{m}$ (secondary follicles). Follicular growth between groups is presented as difference in mean diameter of follicle compared to day 0 of culture. Analysis of variance was used for comparison of means. The Kaplan Meier estimate and log-rank test were used to compute and compare survival over time between all three groups. All statistics were computed with Stata12 software. Statistical difference was defined as $p<0.05$.

\section{Results}

Ovarian endothelial cell isolation and creation of serumfree culture system

Two approaches were tested for isolation of ovarian endothelial cells: Immunomagnetic sorting and FACS. Using conventional monoparametric labeling with magnetic particles for isolation, we established a CD31 positive cell population from B6 mouse ovaries. An average of $2 \%$ CD31 positive cells were acquired $\left(1 \times 10^{4}\right.$ $3 \times 10^{4}$ cells per mouse) per isolation experiment. After 6 passages all cells were scanned by FACS. On average,
93\% of cells were CD 31 positive, VE-Cadherin positive and CD45 negative (Fig. 1b).

We established a second, high fidelity approach to purify and immediately profile ECs from an in-vivo source by FACS. After intra-vital staining with VEcadherin, and post digestion staining with CD31 and CD45, an average of $3 \%$ VE-cadherin positive, CD31 positive and CD45 negative cells were obtained $\left(1 \times 10^{4}\right.$ $2 \times 10^{4}$ cells per mouse). After 6 passages all cells were scanned by FACS. On average, $95 \%$ of the cells were CD 31 positive, VE-Cadherin positive and CD45 negative, superior purities compared to magnetic isolation.

Primary endothelial cell cultivation is a great challenge. In our experience, non-activated POEC could not last more than two passages, insufficient for any in vitro coculture studies. To circumvent this problem without adding growth factors that may confound follicular growth, POECs were transduced with an adenovirus gene, myr-Akt, which leads to constitutive activation of Akt and enables co-culturing of POEC with follicles in serum and growth factors-free medium for weeks, while maintaining their ovarian angiogenic signature (Fig. 1a).

\section{Ovarian Endothelial cell characterization}

Relative mRNA expression of endothelial cell markers such as VEGF-A, VWF and VE-Cadherin further confirm that our AOECs match a known EC phenotype (Fig. 2).

In comparing AOECs to fresh ovarian ECs from follicular and luteal phases of the estrous cycle, endothelial cell markers had comparable expression in AOECs relative to the fresh groups. Relative expression of selected angiocrines that may be involved in early folliculogenesis such as VEGF-A and Notch ligand jagged-1 were relatively comparable in AOEC and fresh ECs. Other angiocrines such as VE-Cadherin, FGF-1, VWF and Dll-1 were relatively up regulated in the AOEC group (Fig. 2).

\section{Follicular and oocyte growth in culture systems}

Co-culture with AOEC did enhance primary follicular growth in comparison to Matrigel and Gel culture systems (Fig. 3b). Primary follicles co-cultured with AOECs grew an average of $33 \mu \mathrm{m}$, a significant increase in growth after day 4 of culture in comparison to the other two groups (Fig. 3c). Following day 10 primary follicles on matrigel collapsed and diameters couldn't be measured. Secondary follicles grew an average of $15 \mu \mathrm{m}$, however, their growth plateaued on day 6 of culture (Fig. 3d). Both control groups had a significant decline in follicular diameter in both follicular classes.

AOECs also promoted oocyte growth, however, predominantly in primary follicles. Initial oocyte diameters in primary and secondary follicles co-cultured with 


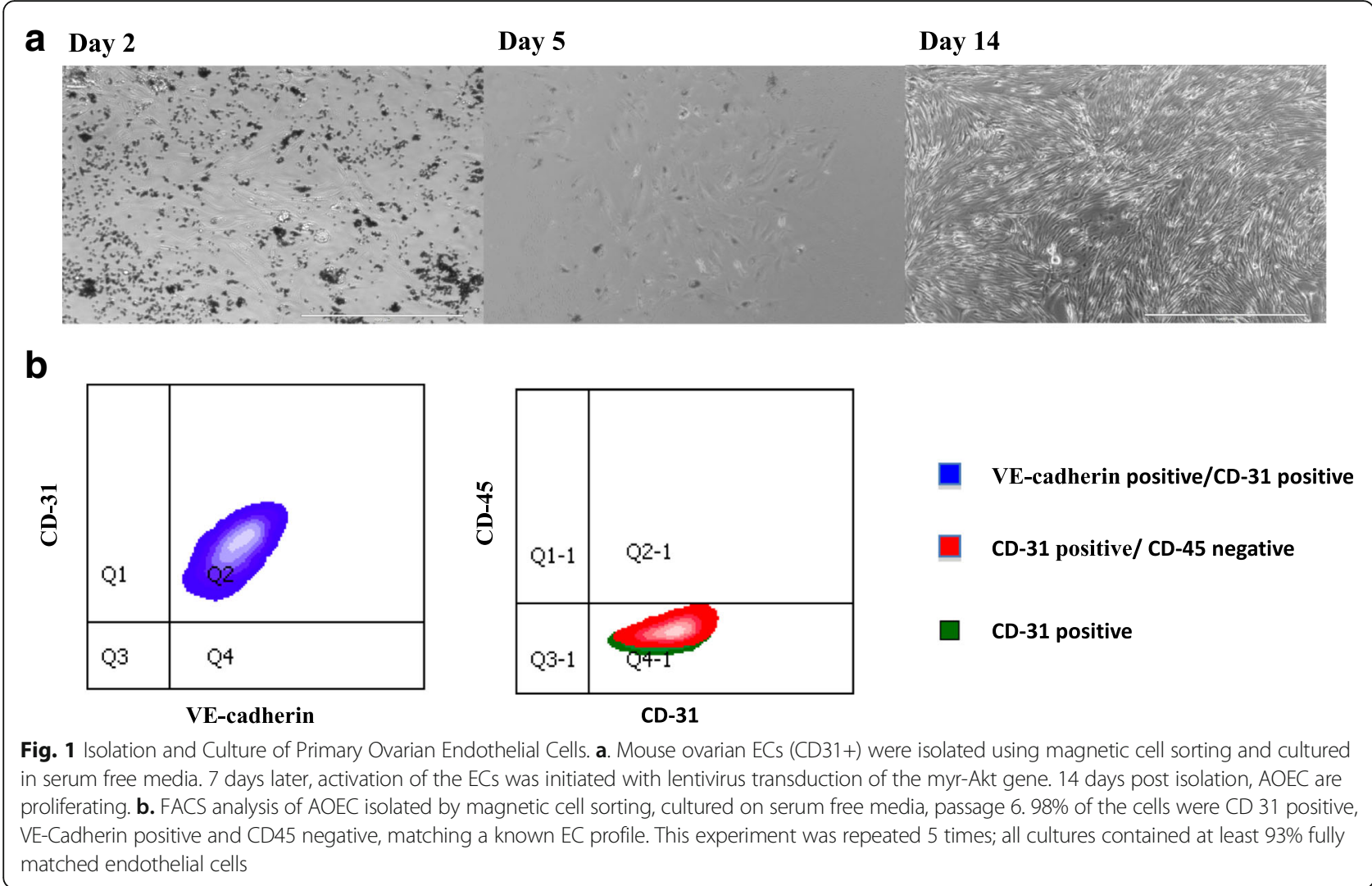

AOEC were $34 \pm 2.7 \mu \mathrm{m}$ and $50 \pm 1.8 \mu \mathrm{m}$, with growth of 60 and $20 \%$ respectively (Fig. $4 \mathrm{a}-\mathrm{b}$ ). Oocytes from cocultured secondary follicles had similar diameters as the matrigel group but both were significantly larger than the gel group.

\section{Follicular survival}

AOEC co-culture maintained the survival of primary and secondary follicles throughout the culture period (Fig. 5a-b). After 14 days of culture with AOEC, 73 and $83 \%$ of the follicles survived respectively. However, most

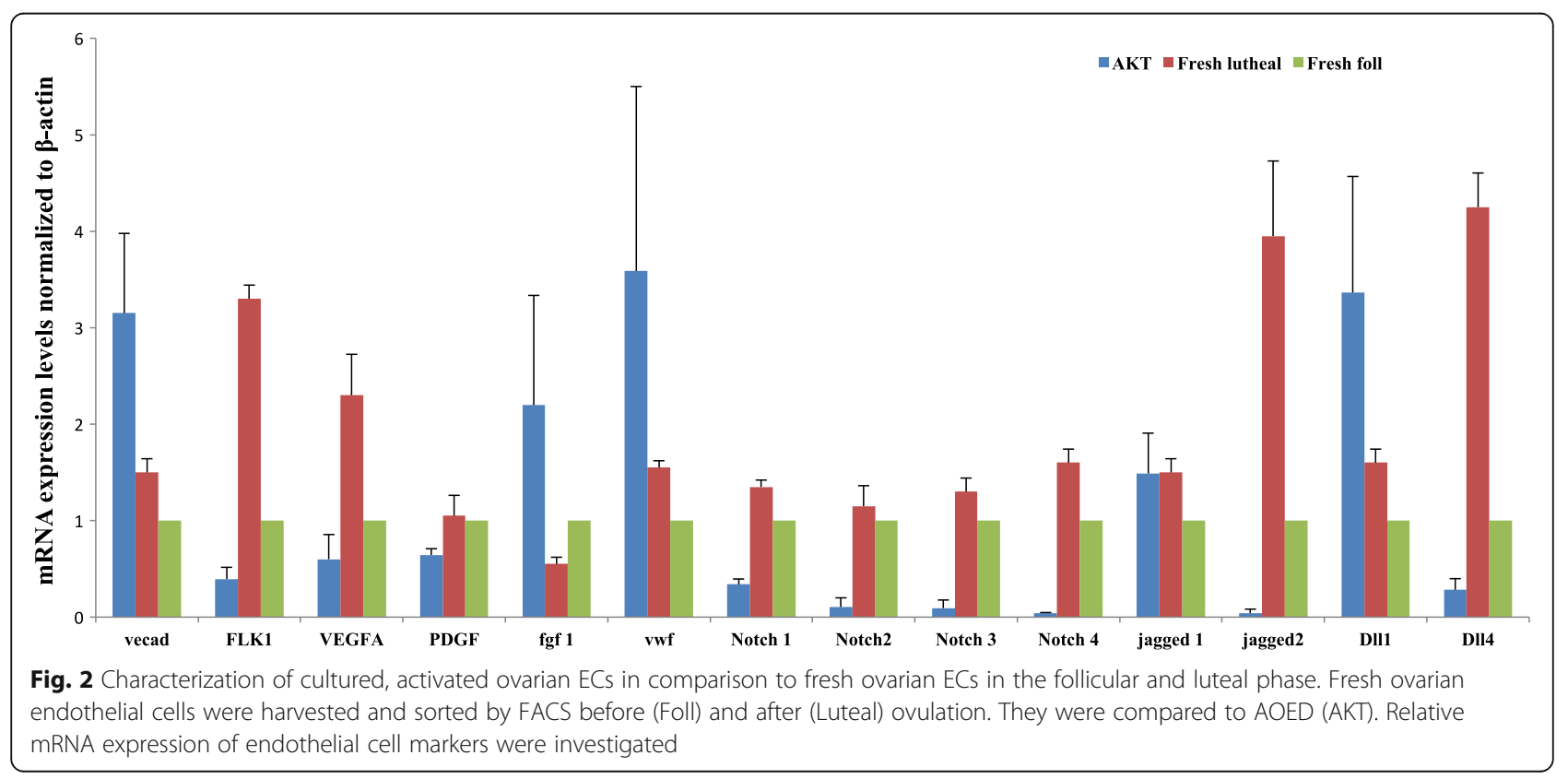




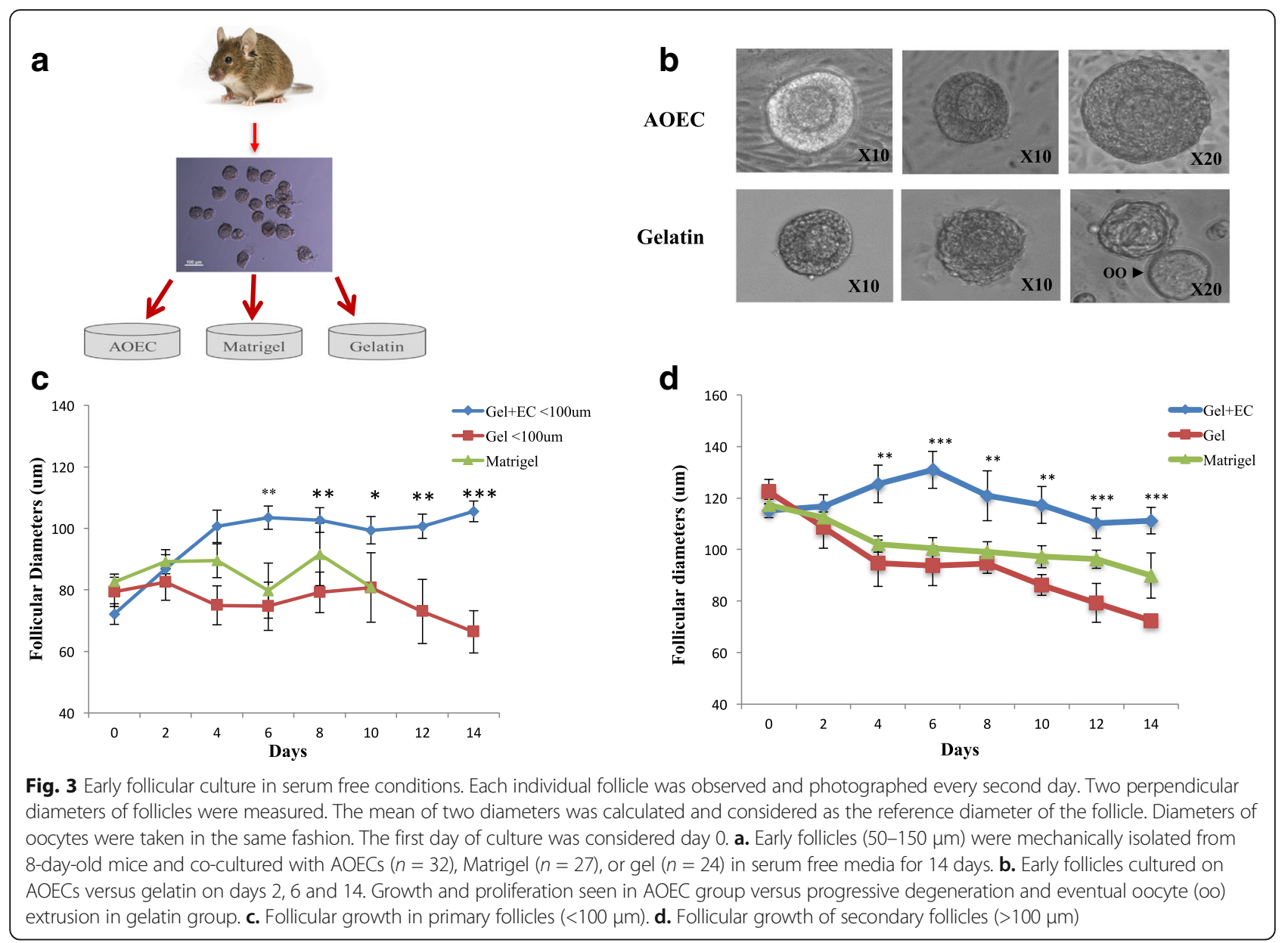

of the follicles cultured on gel or matrigel groups did not survive (primary follicles 0 and 7\%; secondary follicles 12 and 22\%, respectively).

\section{Follicular estrogen secretion}

In order to evaluate the capacity of the follicles to secrete hormones, we analyzed growth media every other day of culture for estradiol levels. Due to undetectable levels of Estradiol in primary follicles and from individual follicles, we cultured 5 secondary follicles $(100-150 \mu \mathrm{m})$ in each well. Increasing levels of estradiol were detected only in media collected from AOEC co-cultured follicles starting day 2 of culture (peak estradiol concentration of $224 \pm 48$ pg/ml) (Fig. 4c).

\section{Assessment of apoptosis or proliferation in granulosa cells and oocytes}

In an attempt to investigate how AOECs promote in vitro development and survival of early follicles in comparison to co-culture with another cell type, we stained early follicles after 7 days of co-culture with AOEC or MTF with TUNEL (detection of DNA fragmentation) and Ki67 (stains proliferating cells).
TUNEL reaction and Ki67 stain showed that follicles cultured on AOEC had significantly less DNA fragmentation and more cells in a proliferative phase than those cultured on MTF (Fig. 6).

\section{Discussion}

It is now evident that the endothelium is more than an inert conduit for blood flow. Tissue-specific endothelial cells, by expressing unique repertoires of trophic growth factors, known as angiocrine factors, support the homeostasis and regeneration of different tissues $[10,15,18,19]$. This is the first attempt to isolate and explore the distinctive characteristics of ovarian endothelial cells. We established a novel primary mouse ovarian AKT-activated EC culture, in serum free conditions, matching a known EC profile. By co-culturing early follicles with our AOECs, we present a platform with which to interrogate the role of ovarian ECs in early folliculogenesis, as well as enhance follicular growth and survival.

The microvascular circulation of the ovary contains micro-cappilaries that connect arteries to veins and the lymphatic system. Reliable isolation is the first step in establishing a primary ovarian endothelial cell culture system. In 


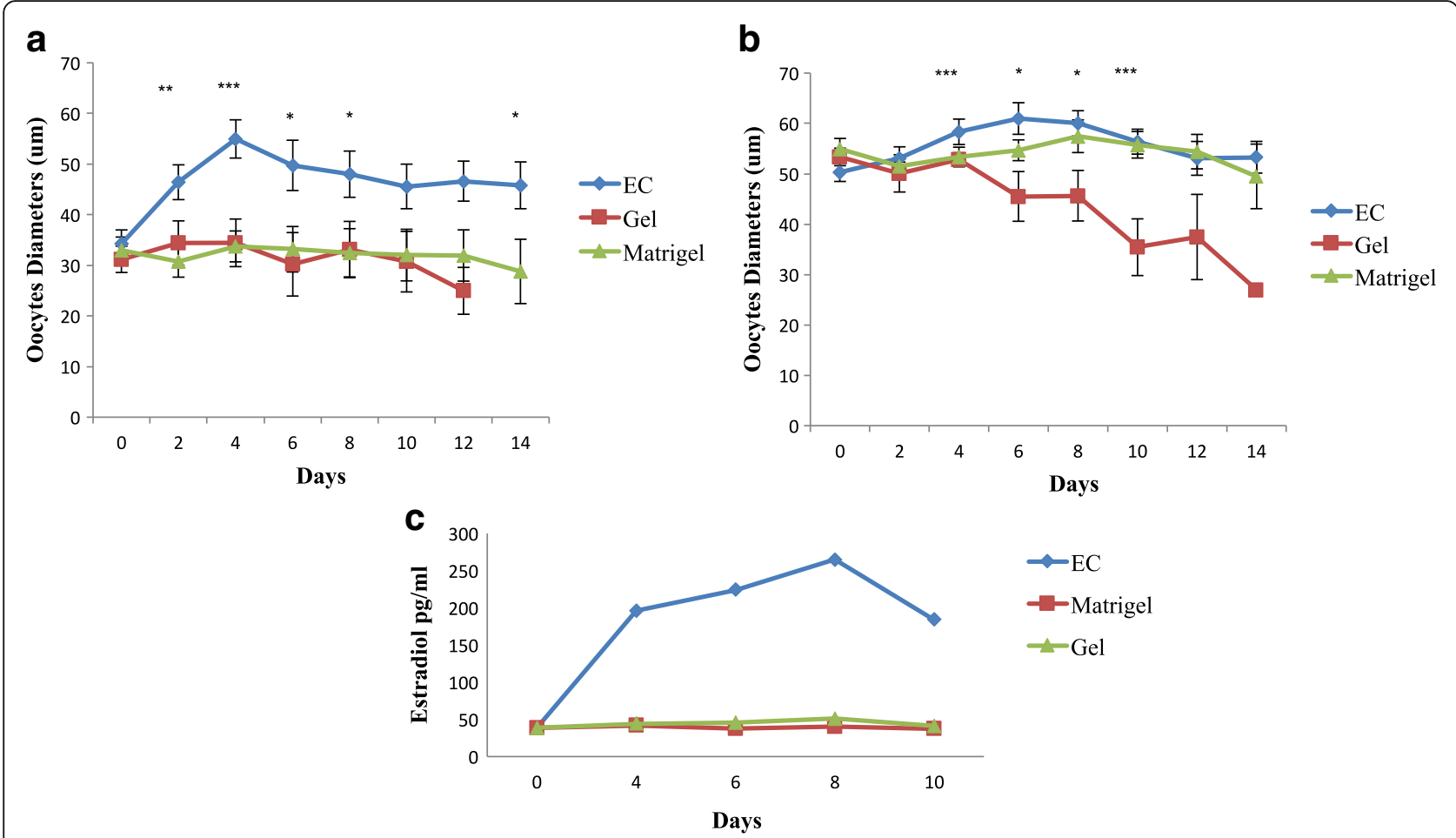

Fig. 4 a. Oocyte growth and estradiol concentrations. a Oocyte growth of oocytes $<45 \mu \mathrm{m}$ b. Oocytes growth of oocytes $>45 \mu \mathrm{m}$ c. Follicular estradiol secretion. Due to undetectable levels of Estradiol in primary follicles and from individual follicles, we cultured 5 secondary follicles (100-150 $\mu \mathrm{m})$ in each well

this study, two approaches were tested for isolating ovarian endothelial cells: First, conventional monoparametric labeling with magnetic particles was employed. This inexpensive and accessible approach acquired an average of $2 \% \mathrm{CD}-31+$ cells with an average $1 \times 10^{4}$ cells per mouse. On average, 10 ovaries were needed in order to isolate a critical mass of ECs for an efferent culture. This fact makes autologous ECs culture almost impossible at this point. These isolations resulted in an average of 93\% CD 31 positive, VE-Cadherin positive and CD45 negative cells after 6 passages, making it a suitable and reliable method for production of an ovarian endothelial cell culture system. It should be emphasized that using this method all types of ovarian ECs (artery, vein and lymph) are isolated. Our laboratory, however, has recently established a second, high fidelity approach to purifying and immediately profiling ECs from an in vivo source by FACS sorting after intravital staining with VE-cadherin and post digestion staining with CD31 and CD45 [24]. This technique resulted in superior purities compared to magnetic isolation (on average, $95 \%$ of the cells were CD 31 positive, VE-Cadherin positive and CD45 negative) The animals are killed $10 \mathrm{~min}$ after infusion of monoclonal antibodies to EC-specific surface markers in order to avoid leakage of antibodies into the lymphatic vessels. Therefore, in experiments undertaken to profile and characterize purified POECs, FACS isolation was used in lieu of magnetic isolation.
Building a reliable culture system also demands an effective cultivation of POECs that maintains survival and proliferation of the endothelial cells. Previously existing models designed to interrogate the role of endothelial cells in proliferation of solid tumors have been carried out in culture conditions that require supplementation of serum and various growth factors such as VEGFA, FGF2 and EGF which may serve as confounding factors when co-culturing with other cell types [25-27]. In order to circumvent using serum and growth factors, long-lasting endothelial cell cultures have been generated by using oncogenic factors including simian virus 40 large $\mathrm{T}$ antigen [28], polyoma middle-T [29] and telomerase reverse transcriptase [30]. Propagation of endothelial cells via these approaches results in chronic activation of the MAPK signaling pathway, which leads to generation of highly proliferative endothelial cells that have lost their innate angiogenic features. Evading these hurdles would require a new approach to generation of a stable endothelial cell culture that could propagate without oncogenic transformation or need for additional growth factors [22]. This goal is achieved by transducing primary endothelial cells with the E4ORF1 gene of the adenovirus serotype 5 or 9 or introduction of myr-AKT which results in constitutive activation of AKT but not MAPK [22]. The availability of a robust population of endothelial cells that retain their innate angiogenic 


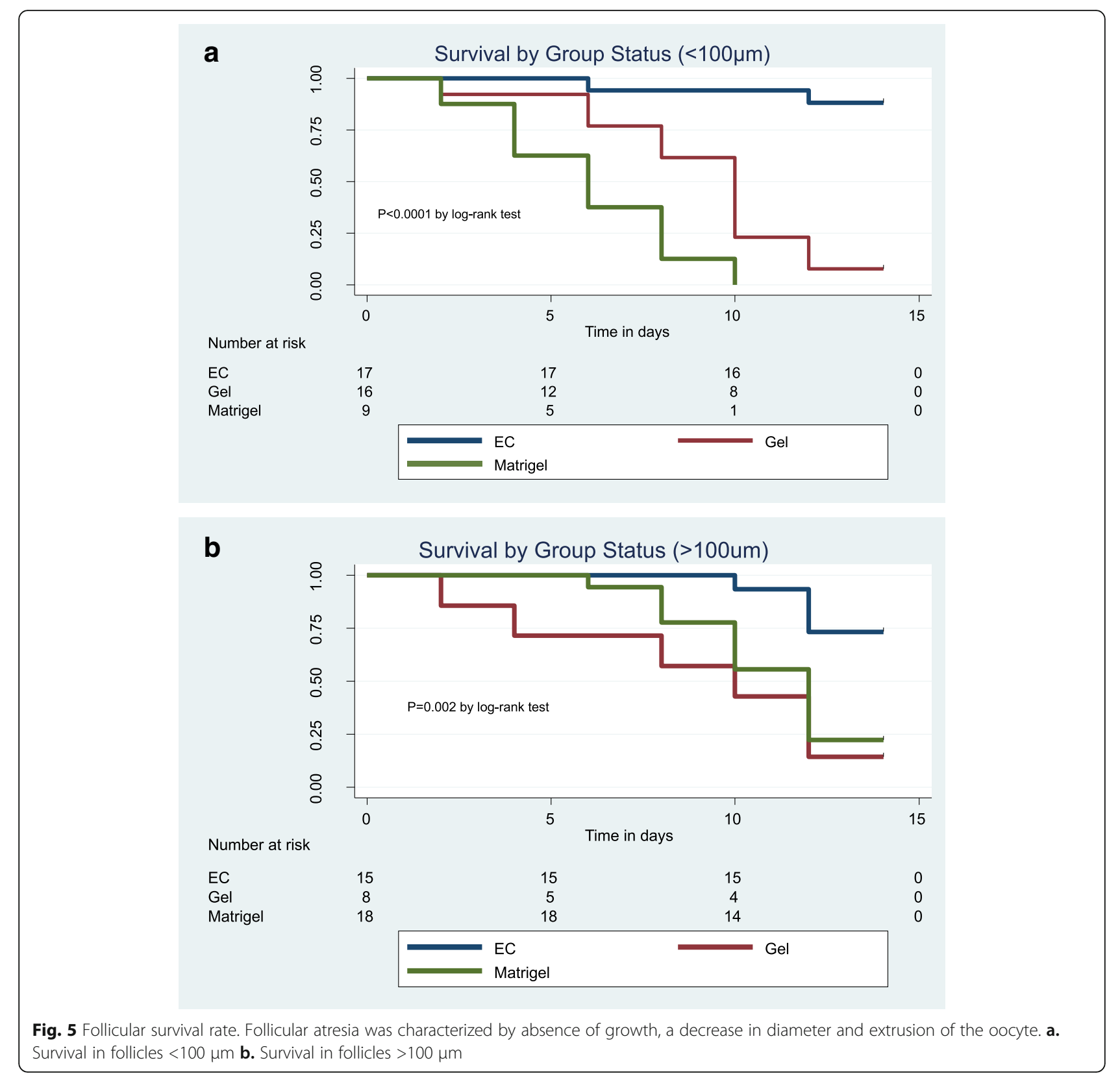

features and are maintained without serum or growth factors is critical in the in vitro study of the role of ECs in organogenesis, tumorogenesis and cell growth. In our study, the angiogenic profile of AKT-activated ovarian ECs was similar, but not identical to that of fresh ovarian ECs (Fig. 2). While this may potentially confound follicular growth, currently, there is no more effective way to propagate and maintain an adequate culture of endothelial cells appropriate for co-culture without addition of growth factors.

One concern that could be raised is that the angiogenic profile of AKT-activated ovarian endothelial cells was similar, but not identical to that of fresh ovarian endothelial cells. However, the expression of selected angiocrines that may be involved in early folliculogenesis (VEGF-A and Notch ligand jagged-1) were relatively comparable in AOEC and fresh ECs. In addition, VECadherin, FGF-1, VWF and Dll-1 were even up regulated in the AOEC group. Since ovarian endothelial cells play a central role in neovascularization during follicular development, as demonstrated in mice [31], the comparable expression of angiocrines between AOEC and fresh $\mathrm{EC}$ is essential.

Follicle culture systems for mouse [32-34], large animals [35, 36] and humans [37] have been developed in both 2-dimensional (2D) and 3-dimensional (3D) formats. 


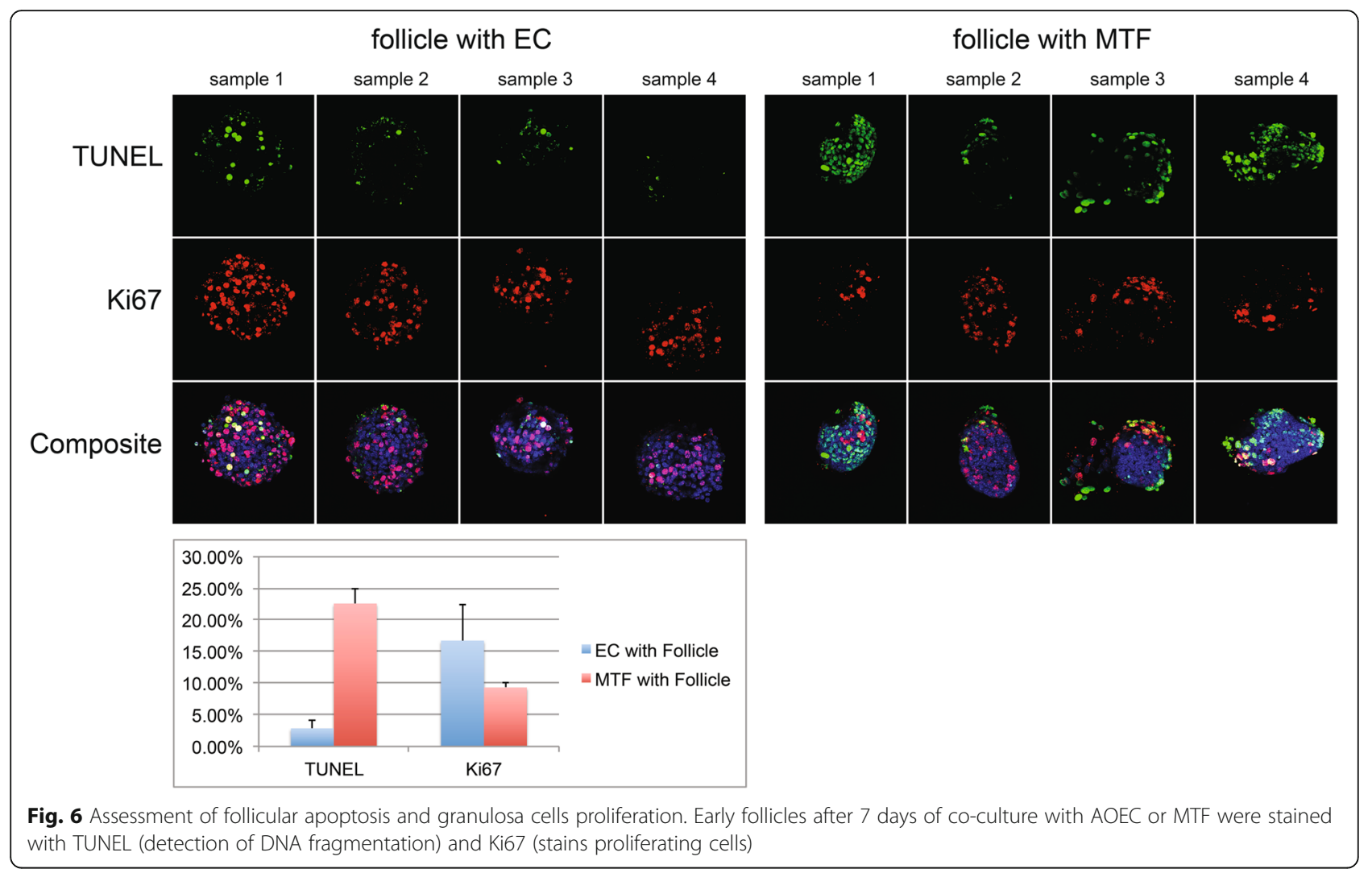

These systems have been successful in supporting the development of primary and early secondary follicles, but have not yet been adapted for routine use due to several limitations. One hurdle in establishing an effective IVM system is determining an optimal approach to primordial follicle activation/recruitment. The primordial follicle contains an oocyte arrested in the dictyate stage of meiosis, a single layer of squamous granulosa cells and a basal lamina, creating a microenvironment in which the granulosa cells and oocyte co-exist [38]. Paracrine communication between the oocyte, its granulosa cells, adjacent thecal cells and surrounding follicles all combine to control primordial follicle recruitment [38]. This communication is largely mediated by secreted growth factors including several members of the transforming growth factor-beta (TGF 3 ) superfamily [39]. However, the role of the vascular niche in early follicular activation and development has yet to be investigated. In order to properly investigate the role of a vascular niche in early follicle activation, one would ideally create a model of isolated primordial follicles grown in co-culture with endothelial cells. However, we found mechanical isolation of intact primordial follicles very challenging. Enzymatic isolation also proved challenging, as follicles rarely retained their intact structure. Several studies have circumvented this challenge by creating a two-step culture system where by primordial follicles are grown in a slice of intact ovary and then isolated once they reach the primary or early secondary phases $[40,41]$. Since our group was interested in intimate and direct communication between follicles and endothelial cells, this method of culture was not suitable.

Another challenge of IVM is re-creating a 3-D environment in which cell-cell and cell-matrix interactions can efficiently take place. Historically, non-spherical (2D) culture systems using gel-coated dishes or membranes coated with extracellular matrix proteins were developed with excellent results, including the growth of primary follicles to complete maturation, fertilization and developmental competence [32, 33, 42]. However, follicles cultured in 2-D systems only partially maintained their spatial configuration and relationships, letting the follicular cells expand at the bottom of the dish, with the consequence of potential loss of oocytefollicular cell interactions. To address this issue, spherical (3-D) culture systems have been developed including matrigel [23], collagen matrix [43], calcium alginate matrix [44] and hyaluronan hydrogel [45]. In choosing controls for this study, we chose gel coated wells for a 2D control and Matrigel for a 3D control, as both are commonly used and approachable systems for follicle culture. We chose not to incorporate our AOECs into a $3 \mathrm{D}$ culture, as this would have presented an additional confounding factor in follicular development and interaction with the ECs. 
Despite existing in a 2D system, we found that a system incorporating co-culture on AOECs was superior to both the $2 \mathrm{D}$ gel system and the $3 \mathrm{D}$ matrigel system in maintaining survival and growth of primary and early secondary follicles. Previous reports of 2-D culture systems have described pre-antral follicle survival rates of $48-68 \%$ [23, 46, 47] We achieved rates as high as 73\% in co-cultured follicles $<100 \mathrm{um}$ and $83 \%$ in co-cultured follicles $>100$ um. These were significantly higher than survival rates in either control group (Fig. 5a, b).

Co-cultured primary follicles showed expeditious growth between days zero and six with a plateau thereafter. Co-cultured secondary follicles showed a milder increase. This observation suggests that factors secreted by ECs may influence growth initiation and maintenance in earlier follicles even more so than more developed follicles. This finding further illustrates the importance of future studies geared towards learning EC influence on primordial follicle activation.

Observation of oocyte growth in addition to total follicle growth suggests that ECs may influence both oocyte growth and granulosa cell proliferation (Fig. 4a-b; Fig. 6). Higher estrogen production in co-cultured follicles provides an objective marker of granulosa cell function (Fig. 4c).

In identifying mechanisms by which ECs may contribute to improved survival and growth of early follicles, several angiocrines may be implicated, including VEGFA and Notch ligands Jagged 1, Dll 1 and Dll4. The importance of VEGF for survival and growth of early and advanced follicles has been reported [48]. Additionally, some suggest VEGF may inhibit apoptosis [49]. Presence of VEGF-A receptors on granulosa cells suggests the factor may promote proliferation events as well as play a potential role in primordial follicle activation in humans [50]. Interestingly, we noted that ECs derived from ovaries in the luteal phase expressed relatively more VEGF than the AOECs or fresh follicular ECs. This may be reflective of VEGF's role in cyclic changes during formation and regression of the corpus luteum. Co-culturing early follicles with ovarian ECs provides this important angiocrine without need for supplementation.

Another potential mechanism to consider is interaction of follicular Notch with its ligands. There are four Notch receptors (Notch 1-4) and two families of ligands: Jagged 1, 2 and Delta-like (Dll) 1,3,4. Recent data shows that multiple Notch genes are expressed in early follicles and are regulated during the time of follicle formation [51]. In addition, attenuating Notch signaling by Notch signaling inhibitors decrease in-vitro follicular development $[51,52]$. Lentivirus mediated overexpression of Notch intracellular domain 2 and cmyc could promote the proliferation of granulosa cells [52]. While roles for Notch in regulating folliculogenesis are beginning to emerge from mouse genetic models
[53], the influence of extra-follicular exposure to Notch ligands on the follicle and its role in in-vitro growth and maintenance of isolated early follicles remains unknown. We show that AOECs express Jagged-1, Dll4 and Dll1 mRNA at a comparable level as fresh ovarian ECs. Therefore, we suggest that activation of Notch may contribute to the maintained growth and survival of early co-cultured follicles.

\section{Conclusions}

We have established a novel platform that allows study of follicle-endothelial cell communication. Furthermore, we have demonstrated that co-culture with activated ovarian endothelial cells enables culture of primary and early secondary mouse ovarian follicles. This novel culture system not only adds to the growing number of described in vitro maturation systems, but also may facilitate the identification of factors that promote early follicular growth, potentially leading to new strategies for fertility preservation.

Funding

No external funding was received for this study.

Availability of data and materials

The datasets used and/or analysed during the current study available from the corresponding author on reasonable request.

\section{Authors' contributions}

$A K$ and $A A B$ wrote the manuscript. $A K, A A B$ designed the experiments; $A K$, $A A B, P G, D W, B S D, R L, D C$, and VS performed the experiments; $R S$ and $Z R$ participated in the analysis and discussion of the results. All authors read and approved the final version of the manuscript.

\section{Ethics approval}

All experiments were performed in strict accordance with the Ethics Committee at Weill Cornell Medical collage. The Institutional Committee of Weill Cornell Medical collage approved the experimental protocols (protocol \#2009-0061). All efforts were made to minimize the number of animals used and their suffering.

Consent for publication Not applicable.

\section{Competing interests}

The authors declare that they have no competing interests.

\section{Publisher's Note}

Springer Nature remains neutral with regard to jurisdictional claims in published maps and institutional affiliations.

\section{Author details}

${ }^{1}$ The Center for Reproductive Medicine and Infertility, Weill Cornell Medical College, New York, NY 10021, USA. ${ }^{2}$ Ansary Stem Cell Center for Regenerative Medicine at Weill Medical College of Cornell University, New York, USA.

Received: 9 June 2017 Accepted: 31 August 2017

Published online: 19 September 2017

\section{References}

1. Abir R, Fisch B, Raz A, Nitke S, Ben-Rafael Z. Preservation of fertility in women undergoing chemotherapy: current approach and future prospects. J Assist Reprod Genet. 1998;15:469-77. 
2. Donnez J, Dolmans MM, Demylle D, Jadoul P, Pirard C, Squifflet J, MartinezMadrid B, van Langendonckt A. Livebirth after orthotopic transplantation of cryopreserved ovarian tissue. Lancet. 2004;364:1405-10.

3. Meirow D, Levron J, Eldar-Geva T, Hardan I, Fridman E, Zalel Y, Schiff E, Dor J. Pregnancy after transplantation of cryopreserved ovarian tissue in a patient with ovarian failure after chemotherapy. N Engl J Med. 2005;353:318-21.

4. Demeestere I, Simon P, Emiliani S, Delbaere A, Englert Y. Orthotopic and heterotopic ovarian tissue transplantation. Hum Reprod Update. 2009;15:649-65.

5. Nugent D, Newton H, Gallivan L, Gosden RG. Protective effect of vitamin E on ischaemia-reperfusion injury in ovarian grafts. J Reprod Fertil. 1998;114:341-6.

6. Yang $\mathrm{H}$, Lee HH, Lee HC, Ko DS, Kim SS. Assessment of vascular endothelial growth factor expression and apoptosis in the ovarian graft: can exogenous gonadotropin promote angiogenesis after ovarian transplantation? Fertil Steril. 2008;90:1550-8.

7. Bastings L, Beerendonk CC, Westphal JR, Massuger LF, Kaal SE, van Leeuwen FE, Braat DD, Peek R. Autotransplantation of cryopreserved ovarian tissue in cancer survivors and the risk of reintroducing malignancy: a systematic review. Hum Reprod Update. 2013;19:483-506.

8. Lammert E, Cleaver O, Melton D. Induction of pancreatic differentiation by signals from blood vessels. Science. 2001;294:564-7.

9. Makita T, Sucov HM, Gariepy CE, Yanagisawa M, Ginty DD. Endothelins are vascular-derived axonal guidance cues for developing sympathetic neurons. Nature. 2008:452:759-63.

10. Matsumoto K, Yoshitomi H, Rossant J, Zaret KS. Liver organogenesis promoted by endothelial cells prior to vascular function. Science. 2001;294:559-63.

11. Sakaguchi TF, Sadler KC, Crosnier C, Stainier DY. Endothelial signals modulate hepatocyte apicobasal polarization in zebrafish. Curr Biol. 2008;18:1565-71.

12. Butler JM, Kobayashi H, Rafii S. Instructive role of the vascular niche in promoting tumour growth and tissue repair by angiocrine factors. Nat Rev Cancer. 2010;10:138-46.

13. Butler JM, Nolan DJ, Vertes EL, Varnum-Finney B, Kobayashi H, Hooper AT, Seandel M, Shido K, White IA, Kobayashi M, et al. Endothelial cells are essential for the self-renewal and repopulation of Notch-dependent hematopoietic stem cells. Cell Stem Cell. 2010;6:251-64.

14. Hooper AT, Butler JM, Nolan DJ, Kranz A, lida K, Kobayashi M, Kopp HG, Shido K, Petit I, Yanger K, et al. Engraftment and reconstitution of hematopoiesis is dependent on VEGFR2-mediated regeneration of sinusoidal endothelial cells. Cell Stem Cell. 2009:4:263-74.

15. Kobayashi H, Butler JM, O'Donnell R, Kobayashi M, Ding BS, Bonner B, Chiu VK, Nolan DJ, Shido K, Benjamin L, Rafii S. Angiocrine factors from Aktactivated endothelial cells balance self-renewal and differentiation of haematopoietic stem cells. Nat Cell Biol. 2010;12:1046-56.

16. Shen Q, Goderie SK, Jin L, Karanth N, Sun Y, Abramova N, Vincent P, Pumiglia K, Temple S. Endothelial cells stimulate self-renewal and expand neurogenesis of neural stem cells. Science. 2004;304:1338-40.

17. Dias S, Hattori K, Heissig B, Zhu Z, Wu Y, Witte L, Hicklin DJ, Tateno M, Bohlen P, Moore MA, Rafii S. Inhibition of both paracrine and autocrine VEGF/ VEGFR-2 signaling pathways is essential to induce long-term remission of xenotransplanted human leukemias. Proc Natl Acad Sci U S A. 2001;98:10857-62.

18. Gilbertson RJ, Rich JN. Making a tumour's bed: glioblastoma stem cells and the vascular niche. Nat Rev Cancer. 2007;7:733-6.

19. Ding BS, Nolan DJ, Butler JM, James D, Babazadeh AO, Rosenwaks Z, Mittal V, Kobayashi H, Shido K, Lyden D, et al. Inductive angiocrine signals from sinusoidal endothelium are required for liver regeneration. Nature. 2010;468:310-5.

20. Suzuki T, Sasano H, Takaya R, Fukaya T, Yajima A, Nagura H. Cyclic changes of vasculature and vascular phenotypes in normal human ovaries. Hum Reprod. 1998;13:953-9.

21. Araujo VR, Duarte $A B$, Bruno JB, Pinho Lopes $C A$, de Fiqueiredo JR. Importance of vascular endothelial growth factor (VEGF) in ovarian physiology of mammals. Zygote. 2013;21:295-304.

22. Seandel M, Butler JM, Kobayashi H, Hooper AT, White IA, Zhang F, Vertes EL, Kobayashi M, Zhang Y, Shmelkov SV, et al. Generation of a functional and durable vascular niche by the adenoviral E4ORF1 gene. Proc Natl Acad Sci U S A. 2008;105:19288-93.

23. Oktem O, Oktay K. The role of extracellular matrix and activin-A in in vitro growth and survival of murine preantral follicles. Reprod Sci. 2007;14:358-66.

24. Nolan DJ, Ginsberg M, Israely E, Palikuqi B, Poulos MG, James D, Ding BS, Schachterle W, Liu Y, Rosenwaks Z, et al. Molecular signatures of tissuespecific microvascular endothelial cell heterogeneity in organ maintenance and regeneration. Dev Cell. 2013;26:204-19.
25. Folkman J, Klagsbrun M. Angiogenic factors. Science. 1987;235:442-7.

26. Ferrara N, Gerber HP, LeCouter J. The biology of VEGF and its receptors. Nat Med. 2003;9:669-76.

27. Yancopoulos GD, Davis S, Gale NW, Rudge JS, Wiegand SJ, Holash J. Vascular-specific growth factors and blood vessel formation. Nature. 2000:407:242-8

28. Candal FJ, Rafii S, Parker JT, Ades EW, Ferris B, Nachman RL, Kellar KL. BMEC1: a human bone marrow microvascular endothelial cell line with primary cell characteristics. Microvasc Res. 1996:52:221-34.

29. Oostingh GJ, Schlickum S, Friedl P, Schon MP. Impaired induction of adhesion molecule expression in immortalized endothelial cells leads to functional defects in dynamic interactions with lymphocytes. J Invest Dermatol. 2007;127:2253-8.

30. Nisato RE, Harrison JA, Buser R, Orci L, Rinsch C, Montesano R, Dupraz P, Pepper MS. Generation and characterization of telomerase-transfected human lymphatic endothelial cells with an extended life span. Am J Pathol. 2004;165:11-24.

31. Kizuka-Shibuya F, Tokuda N, Takagi K, Adachi Y, Lee L, Tamura I, Maekawa R, Tamura H, Suzuki T, Owada Y, Sugino N. Locally existing endothelial cells and pericytes in ovarian stroma, but not bone marrow-derived vascular progenitor cells, play a central role in neovascularization during follicular development in mice. J Ovarian Res. 2014;7:10.

32. Eppig JJ, O'Brien MJ. Development in vitro of mouse oocytes from primordial follicles. Biol Reprod. 1996;54:197-207.

33. Eppig JJ, Schroeder AC. Capacity of mouse oocytes from preantral follicles to undergo embryogenesis and development to live young after growth, maturation, and fertilization in vitro. Biol Reprod. 1989;41:268-76.

34. Spears N, Boland NI, Murray AA, Gosden RG. Mouse oocytes derived from in vitro grown primary ovarian follicles are fertile. Hum Reprod. 1994;9:527-32.

35. Newton $\mathrm{H}$, Picton $\mathrm{H}$, Gosden RG. In vitro growth of oocyte-granulosa cell complexes isolated from cryopreserved ovine tissue. J Reprod Fertil. 1999:115:141-50.

36. Telfer EE, Binnie JP, McCaffery FH, Campbell BK. In vitro development of oocytes from porcine and bovine primary follicles. Mol Cell Endocrinol. 2000;163:117-23.

37. Abir R, Nitke S, Ben-Haroush A, Fisch B. In vitro maturation of human primordial ovarian follicles: clinical significance, progress in mammals, and methods for growth evaluation. Histol Histopathol. 2006;21:887-98.

38. Williams CJ, Erickson GF. Morphology and Physiology of the Ovary. In: De Groot LJ, Beck-Peccoz P, Chrousos G, Dungan K, Grossman A, Hershman JM Koch C, McLachlan R, New M, Rebar R, et al., editors. Endotext. South Dartmouth; 2000.

39. McGee EA, Hsueh AJ. Initial and cyclic recruitment of ovarian follicles. Endocr Rev. 2000;21:200-14.

40. Telfer EE, McLaughlin M, Ding C, Thong KJ. A two-step serum-free culture system supports development of human oocytes from primordial follicles in the presence of activin. Hum Reprod. 2008;23:1151-8.

41. McLaughlin M, Telfer EE. Oocyte development in bovine primordial follicles is promoted by activin and FSH within a two-step serum-free culture system. Reproduction. 2010;139:971-8.

42. Cortvrindt R, Smitz J, Van Steirteghem AC. In-vitro maturation, fertilization and embryo development of immature oocytes from early preantral follicles from prepuberal mice in a simplified culture system. Hum Reprod. 1996;11: 2656-66.

43. Gomes JE, Correia SC, Gouveia-Oliveira A, Cidadao AJ, Plancha CE. Threedimensional environments preserve extracellular matrix compartments of ovarian follicles and increase FSH-dependent growth. Mol Reprod Dev. 1999;54:163-72.

44. Xu M, Barrett SL, West-Farrell E, Kondapalli LA, Kiesewetter SE, Shea LD, Woodruff TK. In vitro grown human ovarian follicles from cancer patients support oocyte growth. Hum Reprod. 2009;24:2531-40.

45. Desai N, Abdelhafez F, Calabro A, Falcone T. Three dimensional culture of fresh and vitrified mouse pre-antral follicles in a hyaluronan-based hydrogel: a preliminary investigation of a novel biomaterial for in vitro follicle maturation. Reprod Biol Endocrinol. 2012;10:29.

46. Ola SI, Ai JS, Liu JH, Wang Q, Wang ZB, Chen DY, Sun QY. Effects of gonadotrophins, growth hormone, and activin A on enzymatically isolated follicle growth, oocyte chromatin organization, and steroid secretion. Mol Reprod Dev. 2008;75:89-96

47. Haidari K, Salehnia M, Rezazadeh Valojerdi M. The effect of leukemia inhibitory factor and coculture on the in vitro maturation and ultrastructure 
of vitrified and nonvitrified isolated mouse preantral follicles. Fertil Steril. 2008;90:2389-97.

48. Bruno JB, Celestino JJ, Lima-Verde IB, Lima LF, Matos MH, Araujo VR, Saraiva MV, Martins FS, Name KP, Campello CC, et al. Expression of vascular endothelial growth factor (VEGF) receptor in goat ovaries and improvement of in vitro caprine preantral follicle survival and growth with VEGF. Reprod Fertil Dev. 2009;21:679-87.

49. Danforth DR, Arbogast LK, Ghosh S, Dickerman A, Rofagha R, Friedman Cl. Vascular endothelial growth factor stimulates preantral follicle growth in the rat ovary. Biol Reprod. 2003;68:1736-41.

50. Abir R, Ao A, Zhang XY, Garor R, Nitke S, Fisch B. Vascular endothelial growth factor $A$ and its two receptors in human preantral follicles from fetuses, girls, and women. Fertil Steril. 2010;93:2337-47.

51. Trombly DJ, Woodruff TK, Mayo KE. Suppression of Notch signaling in the neonatal mouse ovary decreases primordial follicle formation. Endocrinology. 2009;150:1014-24.

52. Zhang CP, Yang JL, Zhang J, Li L, Huang L, Ji SY, Hu ZY, Gao F, Liu YX. Notch signaling is involved in ovarian follicle development by regulating granulosa cell proliferation. Endocrinology. 2011;152:2437-47.

53. Johnson J, Espinoza T, McGaughey RW, Rawls A, Wilson-Rawls J. Notch pathway genes are expressed in mammalian ovarian follicles. Mech Dev. 2001:109:355-61.

\section{Submit your next manuscript to BioMed Central} and we will help you at every step:

- We accept pre-submission inquiries

- Our selector tool helps you to find the most relevant journal

- We provide round the clock customer support

- Convenient online submission

- Thorough peer review

- Inclusion in PubMed and all major indexing services

- Maximum visibility for your research

Submit your manuscript at www.biomedcentral.com/submit 